\title{
Pernikahan Dini Dalam Perspektif Psikologi Keluarga
}

\author{
Hasyim Iskandar ${ }^{1}$, Alfin Nur Farida ${ }^{2}$ \\ IAI Darusslam Blokagungi Banyuwangi \\ Email : hasyimiskandar@iaida.ac.id ${ }^{1}$, alfinnurafidah@gmail,com ${ }^{2}$
}

\begin{abstract}
Adolescence is an age level, where children are no longer children, but cannot be seen as adults. So adolescence is an age that crosses between the ages of children and adults. At this age there are various changes, which are not easy for a child to deal with without the help and understanding of the parents and adults in general. the expressive function of the family for its members who are in a network. Developments in the technological era, it is very easy for teenagers to fall into free struggles and not a few teenagers who choose to marry at an early age. This research is focused on the community in Tegalsari Village, Tegalsari District, Banyuwangi Regency, on the factors that cause early marriage. In this study, there are two factors that cause early marriage, namely internal factors including: educational factors, biological relationship factors, and pregnancy before time. While the external factors themselves include: economic factors and parental factors.
\end{abstract}

\section{Keywords: Family Psychology, Early Marriage}

\begin{abstract}
Abstrak
Masa remaja merupakan suatu tingkat umur, dimana anak-anak bukan lagi anak, akan tetapi belum dapat dipandang dewasa. Jadi remaja merupakan umur yang menjebatani antara umur anak-anak dan dewasa. Pada umur ini terjadi berbagai perubahan, yang tidak mudah bagi seorang anak untuk menghadapinya tanpa bantuan dan pengertian dari pihak orang tua dan orang dewasa pada umumnya.Keluarga adalah rumah tangga yang memiliki hubungan darah atau perkawinan atau menyediakan terselenggaranya fungsifungsi instrumental mendasar dan fungsi-fungsi ekspresif keluarga bagi para anggotanya yang berada dalam suatu jaringan. Perkembangan di era teknologi, sangat mudah bagi para remaja terjerumus pergalulan bebas dan tak sedikit pula para remaja yang memilih menikah diusia dini. Penelitian ini di fokuskan pada masyarakat di Desa Tegalsari Kecamatan Tegalsari Kabupaten Banyuwangi, pada faktor-faktor penyebab pernikahan dini. Dalam penelitian ini ada dua faktor penyebab pernikahan dini yaitu faktor internal meliputi: Faktor Pendidikan, Faktor Hubungan Biologis, dan Hamil Sebelum Waktunya. Sedangkan Faktor Eksternal itu sendiri meliputi: Faktor Ekonomi, dan Faktor Orang tua.
\end{abstract}

\section{Kata Kunci : Psikologi Keluarga, Pernikahan Dini,}




\section{A. Pendahuluan}

Masa remaja merupakan suatu tingkat umur, dimana anak-anak bukan lagi anak, akan tetapi belum dapat dipandang dewasa. Jadi remaja merupakan umur yang menjebatani antara umur anak-anak dan dewasa. Pada umur ini terjadi berbagai perubahan, yang tidak mudah bagi seorang anak untuk menghadapinya tanpa bantuan dan pengertian dari pihak orang tua dan orang dewasa pada umumnya. (Zakariah Drajat, 1982:28).

Dalam setiap masyarakat manusia, pasti akan dijumpai keluarga batih ("Nuclear family"). Keluarga batih merupakan kelompok sosial terkecil yang terdiri dari suami, istri beserta anak-anaknya yang belum menikah. Keluarga batih tersebut lazimnya juga disebut rumah tangga, yang merupakan unit terkecil dalam masyarakat sebagai wadah dan proses pergaulan hidup. Yang memiliki unsur-unsur system sosial yang pada pokoknya mencakup kepercayaan, perasaan, tujuan, kaidah-kaidah, kedudukan, dan peranan, tingkatan atau jenjang, sanksi, kekuasaan, dan fasilitas. (Soerjono Soekanto, 2009:1).

Pernikahan menurut agama yang resmi adalah pernikahan yang sah secara agama dan tercatat oleh Negara dengan bukti berupa dokumen yang dikeluarkan oleh Negara. Bila menikah secara islam di KUA maka pernikahan dianggap sah secara agama islam dan sah secara sipil (hukum negara). Bukti dokumen dari Negara adalah buku KUA . pasangan agama non islam yang melaporkan pernikahan agamanya ke kantor catatan sipil akan mendapatkan buku dokumen Negara berupa akta pernikahan. (www.desisachiko.com, diakses 02 Maret 2019).

Bukan hanya itu, sering kali pernikahan dini yang biasanya berlangsung tanpa kesiapan mental dari pasangan, yang berakhir pada percerain. Adapun dampaknya pada kesehatan perempuan. Karena dilakukan pada usia muda, sering kalia organ reproduksi perempuan belum siap, sehingga biasanya menyebabkan kesakitan, trauma, seks 
berkelanjutan, pendarahan, keguguran, bahkan sampai yang fatal, kematian ibu saat melahirkan.

Desa Tegalsari merupakan salah satu Desa yang berada di Kecamatan Tegalsari, Kabupaten Banyuwangi, Provinsi Jawa Timur. Secara umum Desa Tegalsari memiliki fasilitas pendidikan yang meliputi : PAUD, SD/.MI, SMP/MTs, SMA/SLTP. Sebagian masyarakatnya tidak heran dengan hal pernikahan dini, terbukti pada beberapa remaja yang masih usia sekolah melakukan pernikahan.

Data dari KUA, yang menyatakan bahwa pernikahan yang terjadi di Desa Tegalsari, Kecamatan Tegalsari, Kabupaten Banyuwangi pelaku beruasia 21 tahun ke bawah. pada tahun 2017 terdaftar nama Sari Fatul Huda yang lahir di Banyuwangi 20 Februari 1998. Itu salah satu contoh pernilkahan dini yang terdaftar di KUA.

Penelitian ini hanya dikonsentrasikan kepada warga masyarakat Desa Tegalsari Kecamatan Tegalsari Kabupaten Banyuwangi. Yang melakukan pernikahan dini yang tercatat di Kantor Urusan Agama (KUA). Realitas inilah yang menarik peneliti untuk melakukan kajian lebih jauh mengenai faktor-faktor penyebab pernikahan dini yang ada di Desa Tegalsari, Kecamatan Tegalsari, Kabupaten Banyuwangi. Tujuan Penelitian ini adalah untuk mengetahui tentang pemikahan dini dalam perspektif Psikologi keluarga

\section{A. Kajian Pustaka}

Batasan penelitian ini terdapat pada tema penelitian, yang hanya fokus pada faktor-Faktor penyebab pernikahan dini. Dan pada objek penelitian dibatasi didesa Tegalsari Kecamatan Tegalsari Kabupaten Banyuwangi.

Psikologi keluarga adalah suatu ilmu untuk mengetahui, mengenal, memahami dan menghayatinya dalam pelaksanaan kehidupan berumah tangga dan berkeluarga serta sadar akan hak, tugas, kewajiban, dan 
tanggung jawab masing. Untuk ini, kesadaran kita terhadap peringatan allah dalam menciptakan makhluk sejak dari adam merupakan kunci pertimbangan dalam kehidupannya. (Fachruddin Hasballlah, 2008:7).

Cini pertama yaitu bahwa orangtua seyogyanya bersikap tidak logis (sa'benere). Artinya orangtua dapat membuktikan apa atau mana yang benar dan yang salah. Sikap tidak logis sebagai contoh, akan mendidik anak agar dia kemudian menjadi orang yang mandiri dan bertanggung jawab. Ciri kedua yaitu bahwa orang tua seyogyanya bersikap tidak etis (sa'mestine). Artinya orangtua bersikap tidak yang didasarkan pada patokan tertentu, sehinnga tidak asal saja atau sembrono. Beberapa ukuran untuk sikap tidak etis itu antara lain: 1) tidak searakah. 2) mampu tidak berkekurangan tetapi juga tidak serba kelebihan. 3) tidak berlarutlarut. Cini ketiga yaitu bahwa orangtua itu seharusnya bersikap tidak etis (sakepenake). Artinya yaitu seharusnya orangtua hidup enak, tanpa menyebabkan ketidak enakan pada pihak lain. (Soejono Soekanto, 2009:6). Peran Ibu Dalam Keluarga, Peran Ayah Dalam Keluarga, Komunikasi dalam keluarga.

1. Pemikahan dini

Faktor-faktor penyebab pernikahan dini dapat dikelompokkan menjadi dua faktor penyebab, yaitu faktor internal dan faktor eksternal.

a. Faktor Internal

1) Pendidikan

Pendidikan anak-anak mempunyai peran yang sangat besar. Jika seseorang anak putus sekolah pada usia wajib sekolah, kemudian mengisi waktu dengan bekerja. Kemudian dia merasa sudah cukup mandiri, maka dia akan merasa mampu untuk menghidupi diri sendiri.

2) Dewasa Sebelum Waktunya 
Pada fase praremaja ini anak-anak sedang membangun hubungan sosial dengan teman-temannya serta mempunyai rasa keingintahuan terhadap segala hal yang dia lihat ataupun didengar. Kemajuan teknologi yang menyuguhkan berbagai tayangan akan membawa dampak positif jika digunakan dengan semestinya, tetapi akan berdampak negatif jika mereka tidak biasa memilah dan memilih. Karena keingintahuannya maka berbagai tontonan yang berbau seks diakses anak-anak usia dibawah 17 tahun, akan menimbulkan anak-anak berfantasy seks dan akan membuat anak-anak "Dewasa” dini.

3) Telah Melakukan Hubungan Biologis

Karena anak-anak telah melakukan hubungan biologis layaknya suami-istri.Dengan kondisi seperti ini, orang tua anak perempuan cenderung segera menikahkan anaknya, karena menurut orang tua anak gadis ini sudah tidak perawan lagi, dan hal ini menjadi aib.

4) Hamil Sebelum Waktunya

Hamil diluar nikah bukan hanya kecelakaan, tapi biasanya juga karena diperkosa sehingga terjadilah hamil diluar nikah. Orang tua yang dihadapkan pada situasi tersebut pastilah akan menikahkan anak gadisnya. (Nginayatul Khasanah, 2017:56).

b. Faktor Eksternal

1) Orang Tua

Orang tua yang mendorong anaknya untuk menikah di usia muda juga disebabkan oleh banyak hal diantaranya yaitu pemahaman agama orang tua. Sebagian orang tua begitu kurang dalam memahami ajaran agamanya dengan dalih, bahwa menikah muda dapat menjauhkan anak dari perbuatan negatif tanpa memedulikan aspek lainnya ataupun yang telah 
ditetapkan.Selain itu, rendahnya tingkat pendidikan orang tua juga memicu terjadinya pernikahan dini.

2) Lingkungan

Anak akan secara alami akan sangat berpengaruh oleh lingkungan di mana dia lahir dan dibesarkan. Watak anak, kebiasaan, dan pola pikir anak akan berkembang sesuai dengan lingkungannya. Oleh karena itu, lingkungan mempunyai peran dalam tumbuh kembangnya anak. Jika lingkungan mayoritas melakukan pemikahan di usia yang masih di bawah umur maka secara otomatis anak tersebut juga melakukan hal yang sama.

3) Ekonomi

Biasanya ini terjadi ketika keluarga si gadis berasal dari keluarga yang kurang mampu.Orangtuanya pun menikahkan si gadis dengan laki-laki dani keluarga mapan. Hal ini tentu akan berdampak baik bagi si gadis maupun orangtuanya. $\mathrm{Si}$ gadis bisa mendapat kehidupan yang layak serta beban orangtuanya bisa berkurang.

4) Media Massa dan Internet

Disadari atau tidak, anak zaman sekarang sangat mudah mengakses segala sesuatu yang berhubungan dengan seks dan semacamnya, hal ini membuat mereka jadi "terbiasa" dengan hal-hal berbau seks dan tidak menganggapnya tabu lagi.

5) Faktor Adat dan Budaya

Faktor ini juga ikut berperan dalam mempenganuhi terjadinya pernikahan dini. Jika dalam budaya setempat mempercayai apabila anak perempuannya tidak segera menikah itu akan memalukan keluarganya karena dianggap tidak laku dalam linggkungannya. Yang kerap disebutnya sebagai perawan tua. 
Faktor ini sudah sudah mulai jarang muncul, tapi pernikahan usia dini di Indonesia perlu mendapat perhatian, pasalnya angka pernikahan dini masih terbilang sangat tinggi.(Nginayatul Khasanah, 2017:56).

\section{B. Metodelogi Penelitian}

Dalam melakukan penelitian atau research diperlukan suatu tempat penelitian untuk memperoleh data yang mendukung tercapainya tujuan penelitian. Adapun yang menjadi tempat penelitian ini, peneliti mengambil lokasi di Desa Tegalsari Kecamatan Tegalsari Kabupaten Banyuwangi dengan alasan:

1. Peran keluarga terhadap pernikahan dini

2. Di KUA terdapat data yang dibutuhkan untuk penelitian Pendekatan Penelitian

Dari ungkapan konsep tersebut jelas bahwa yang dikehendaki adalah suatu informasi dalam bentuk depenelitian. Di samping itu ungkapan konsep tersebut lebih menghendaki makna yang berada dibalik depenelitian tersebut, karena itu penelitian ini lebih sesuai jika menggunakan pendekatan kualitatif. Di sisi lain penelitian ini lebih mempunyai perspektif emic, dengan pengertian bahwa data yang dikumpulkan diupayakan untuk didepenelitiankan berdasarkan ungkapan, bahasa, cara berfikir, pandangan subjek penelitian, sehingga mengungkapkan apa yang menjadi pertimbangan di balik tindakan konversi dalam beragama. (Hamidi, 2004: 70).

\section{Temuan dan Pembahasan}

pernikahan dini dipengaruhi oleh beberapa faktor penyebab diantaranya adalah: Faktor Ekonomi Biasanya ini terjadi ketika keluarga si gadis berasal dari keluarga kurang mampu. Orangtuanya pun menikahkan si gadis dengan laki-laki dari keluarga mapan. Hal ini tentu akan berdampak baik bagi si gadis maupun orangtuanya. Dengan 
harapan $\mathrm{Si}$ gadis bisa mendapat kehidupan yang layak serta beban orangtuanya bisa berkurang.Faktor orangtuaOrang tua yang mendorong anaknya untuk menikah di usia muda juga disebabkan oleh banyak hal diantaranya yaitu pemahaman agama orang tua. Sebagian orang tua begitu kurang dalam memahami ajaran agamanya dengan dalih, bahwa menikah muda dapat menjauhkan anak dari perbuatan negatif tanpa memedulikan aspek lainnya ataupun yang telah ditetapkan. Selain itu, rendahnya tingkat pendidikan orang tua juga memicu terjadinya pernikahan dini, dan Faktor PendidikanPendidikan anak-anak mempunyai peran yang sangat besar. Jika seseorang anak putus sekolah pada usia wajib sekolah, kemudian mengisi waktu dengan bekerja. Kemudian dia merasa sudah cukup mandiri, maka dia akan merasa mampu untuk menghidupi diri sendiri.

Dari pemaparan informan tokoh masyarakat mengatakan adanya remaja yang Hamil diluar nikah bukan hanya kecelakaan, tapi biasanya juga karena diperkosa sehingga terjadilah hamil diluar nikah. Orang tua yang dihadapkan pada situasi tersebut pastilah akan menikahkan anak gadisnya akan tetapi juga disebabkan oleh faktor pergaulan dengan teman sebaya yang berperilaku kurang baik akan menarik mereka ke halhal yang tidak diinginkan. Peran orangtua terhadap anak sangat penting sekali dibutuhkan bagi seorang anak yang beranjak ke remaja.

Untuk pegawai pencatat nikah KUA ketika ada catin yang sudah hamil duluan maka akan diberikan kode yang namanya "Aminuri". Bagi catin yang usianya kurang mencukupi, maka harus membawa surat yang dinyatakan oleh orangtua, yang intinya mendapakan persetujuan melakukan pernikahan. Dan solusi yang bisa ditawarkan oleh pihak KUA terhadap catin yang karena hamil duluan. 'tidak ada yang lebih baik dengan memberikan si jabang bayi untuk menikmati kehidupan di dunia, yang pada nantinya dengan menanggung rasa malu, walaupun pada akhirnya harus menghentikan aktivitasnya sekolah. Setelah melahirkan 
bisa melanjutkan sekolah lagi, terlebih lagi harus fokus pada mengurus si anak sampai dewasa.Agar nantinya mendapatkan kasih sayang dan kehidupan yang layak. Dan akan diberikan pembinaan mengenai pendewasaan usia dini, dalam rangka membentuk keluarga yang sakinah mawadah warrohmah. Dengan adanya pembinaan tersebut dengan harapan nantinya di keluarga setidaknya mengurangi resiko perceraian.

Jadi dari hasil temuan penelitian di Desa Tegalsari Kecamatan Tegalsari Kabupaten Banyuwangi, peneliti bermaksud mendepenelitiankan tentang studi kasus faktor-faktor penyebab pernikahan dini di Desa Tegalsari Kecamatan Tegalsari, dan mengungkapkan hasil temuan dari lapangan yang mengemukakan bahwa sebagai berikut:

Adanya Data yang menyatakan dari Kementrian Urusan Agama (KUA) Tegalsari Kecatamatan Tegalsari Kabupaten Banyuwangi berikut ini adalah data pelaku pernikahan dini yang tercatat di Kantor Urusan Agama (KUA) Desa Tegalsari Kecamatan Tegalsari secara global sebagai berikut:

\begin{tabular}{|c|l|l|l|}
\hline $\begin{array}{c}\mathbf{N} \\
\mathbf{0}\end{array}$ & \multicolumn{1}{|c|}{ Nama Pelaku } & $\begin{array}{c}\text { Tanggal/Bulan } \\
\text { /Tahun }\end{array}$ & \multicolumn{1}{|c|}{ Usia } \\
\hline 1 & Heni Puji Astutik & $\begin{array}{l}\text { 4 September } \\
\text { 2016 }\end{array}$ & $\begin{array}{l}19 \\
\text { Tahun }\end{array}$ \\
\hline 2 & $\begin{array}{l}\text { Halimah Rika } \\
\text { Winata }\end{array}$ & 17Juli 2016 & $\begin{array}{l}\text { 19 } \\
\text { Tahun }\end{array}$ \\
\hline 3 & Yuni Pertiwi & 02 Mei 2016 & $\begin{array}{l}\text { 16 } \\
\text { Tahun }\end{array}$ \\
\hline 4 & $\begin{array}{l}\text { Arum Cahyani } \\
\text { Mulyati }\end{array}$ & 05 Mei 2016 & $\begin{array}{l}\text { 18 } \\
\text { Tahun }\end{array}$ \\
\hline 5 & Dewi Astutik & 05 Mei 2016 & $\begin{array}{l}\text { 18 } \\
\text { Tahun }\end{array}$ \\
\hline 6 & Fransiska Widiyanti & 07Januari 2016 & $\begin{array}{l}\text { 18 } \\
\text { Tahun }\end{array}$ \\
\hline 7 & Evi Nur Avivah & 07Januari 2016 & $\begin{array}{l}\text { 16 } \\
\text { Tahun }\end{array}$ \\
\hline 8 & Nita Arvida & 17Januari 2016 & $\begin{array}{l}\text { 19 } \\
\text { Tahun }\end{array}$ \\
\hline 9 & Retno Wulandari & 22Januari 2019 & $\begin{array}{l}\text { 16 } \\
\text { Tahun }\end{array}$ \\
\hline
\end{tabular}




\begin{tabular}{|c|c|c|c|}
\hline 10 & Eni Kartiana Dewi & 06 Februari 2016 & $\begin{array}{l}19 \\
\text { Tahun }\end{array}$ \\
\hline 11 & & 12 Februari 2016 & $\begin{array}{l}17 \\
\text { Tahun }\end{array}$ \\
\hline 12 & Wiwik Rahayu & 17 Maret 2016 & $\begin{array}{l}19 \\
\text { Tahun }\end{array}$ \\
\hline 13 & $\begin{array}{l}\text { Tita Nuarifki } \\
\text { Cempaka W }\end{array}$ & 0 Mare & $\begin{array}{l}17 \\
\text { Tahun }\end{array}$ \\
\hline 4 & Dwi $A$ & 21April 2016 & \begin{tabular}{|l|}
17 \\
Tahun \\
\end{tabular} \\
\hline 15 & Dewi Lailatun Nisa & $\begin{array}{ll}2 & \text { November } \\
2016 & \\
\end{array}$ & \begin{tabular}{|l|}
19 \\
Tahun
\end{tabular} \\
\hline 16 & Devi I & $\begin{array}{ll}19 & \text { November } \\
2016 & \end{array}$ & $\begin{array}{l}20 \\
\text { Tahun }\end{array}$ \\
\hline 17 & Nur Dwi Lestari & $\begin{array}{ll}21 & \text { November } \\
2016 & \\
\end{array}$ & \begin{tabular}{|l|}
19 \\
Tahun \\
\end{tabular} \\
\hline 18 & $\begin{array}{l}\text { Risna } \\
\text { Yuliastutik }\end{array}$ & 13 Mei 2016 & \begin{tabular}{|l|}
19 \\
Tahun \\
\end{tabular} \\
\hline 19 & Uswatul Fadlia & 22 Mei 2016 & \\
\hline 20 & Risca Masrulainy & 11Juni 2016 & $\begin{array}{l}18 \\
\text { Tahun }\end{array}$ \\
\hline 22 & Mukm & 28 Maret 2 & $\begin{array}{l}20 \\
\text { Tahun }\end{array}$ \\
\hline 23 & Fitri Dwi Handayani & 15Juli 2016 & \begin{tabular}{|l|}
18 \\
Tahun \\
\end{tabular} \\
\hline 24 & Rina Rizatul Aini & $\begin{array}{ll}02 & \text { September } \\
2017 & \\
\end{array}$ & \begin{tabular}{|l}
19 \\
Tahun \\
\end{tabular} \\
\hline 25 & Sulis Tyoningsih & $\begin{array}{ll}08 & \text { September } \\
2017 & \\
\end{array}$ & \begin{tabular}{|l|}
20 \\
Tahun
\end{tabular} \\
\hline 26 & Elly Rizka Amalia & $\begin{array}{ll}08 & \text { September } \\
2017 & \end{array}$ & $\begin{array}{l}20 \\
\text { Tahun }\end{array}$ \\
\hline 27 & Sarifatul Huda & $\begin{array}{ll}08 & \text { September } \\
2017 & \end{array}$ & $\begin{array}{l}19 \\
\text { Tahun }\end{array}$ \\
\hline 28 & mavraut & $\begin{array}{ll}09 & \text { September } \\
2017 & \end{array}$ & \begin{tabular}{|l|}
20 \\
Tahun
\end{tabular} \\
\hline 29 & $\begin{array}{l}\text { Hadi Sucipto dan } \\
\text { Ayu Lestani sama- } \\
\text { sama melakukan } \\
\text { pemikahan dini }\end{array}$ & $\begin{array}{ll}10 & \text { September } \\
2017 & \end{array}$ & \begin{tabular}{|l}
19 \\
Tahun \\
Dan \\
16 \\
Tahun
\end{tabular} \\
\hline 30 & Nurma Yunita & $\begin{array}{ll}13 & \text { September } \\
2017 & \end{array}$ & $\begin{array}{l}18 \\
\text { Tahun }\end{array}$ \\
\hline 31 & Niken Ayu Utari & $\begin{array}{ll}15 & \text { September } \\
2017 & \end{array}$ & \\
\hline
\end{tabular}




\begin{tabular}{|c|c|c|c|}
\hline 32 & Anik Dwi Oktaviana & $\begin{array}{ll}18 & \text { September } \\
2017 & \end{array}$ & $\begin{array}{l}20 \\
\text { Tahun }\end{array}$ \\
\hline 33 & Istika Rahmasari & $\begin{array}{ll}18 & \text { September } \\
2017 & \end{array}$ & $\begin{array}{l}18 \\
\text { Tahun }\end{array}$ \\
\hline 34 & Meita Ratna Sani & $\begin{array}{ll}20 & \text { September } \\
2017 & \end{array}$ & $\begin{array}{l}19 \\
\text { Tahun }\end{array}$ \\
\hline 35 & Sintia Vahrani & 25 Oktober 2017 & $\begin{array}{l}16 \\
\text { Tahun } \\
\end{array}$ \\
\hline 36 & Triya Rahayu & $\begin{array}{ll}03 & \text { November } \\
2017 & \\
\end{array}$ & $\begin{array}{l}19 \\
\text { Tahun }\end{array}$ \\
\hline 37 & $\begin{array}{lll}\text { Bela Ayu } & \text { Dwi } \\
\text { Lestari }\end{array}$ & $\begin{array}{ll}06 & \text { November } \\
2017 & \\
\end{array}$ & $\begin{array}{l}13 \\
\text { Tahun }\end{array}$ \\
\hline 38 & $\begin{array}{l}\text { Nur Laela Azizatul } \\
\text { D }\end{array}$ & $\begin{array}{ll}27 & \text { November } \\
2017 & \\
\end{array}$ & \begin{tabular}{|l|}
17 \\
Tahun \\
\end{tabular} \\
\hline 39 & Ella Kartika & 24 Februari 2018 & $\begin{array}{l}19 \\
\text { Tahun }\end{array}$ \\
\hline 40 & Evi Vinlivia & 24 Februari 2018 & $\begin{array}{l}17 \\
\text { Tahun }\end{array}$ \\
\hline 41 & Yuyun Novita & 04 Maret 2018 & $\begin{array}{l}19 \\
\text { Tahun }\end{array}$ \\
\hline 42 & $\begin{array}{l}\text { Sela Ayu Ulan } \\
\text { Safitri }\end{array}$ & 09 Maret 2018 & $\begin{array}{l}17 \\
\text { Tahun }\end{array}$ \\
\hline 43 & Rika Nova Ulandari & 24 Juni 2018 & $\begin{array}{l}18 \\
\text { Tahun } \\
\end{array}$ \\
\hline 44 & Mesi Prama Sila & 27Juni 2018 & $\begin{array}{l}20 \\
\text { Tahun }\end{array}$ \\
\hline 45 & Dwi Nur Malika & 10 Juli 2018 & $\begin{array}{l}16 \\
\text { Tahun } \\
\end{array}$ \\
\hline 46 & Eni Fitria & $\begin{array}{ll}04 & \text { September } \\
2018 & \\
\end{array}$ & $\begin{array}{l}16 \\
\text { Tahun } \\
\end{array}$ \\
\hline 47 & $\begin{array}{l}\text { Linda Ayu Novita } \\
\text { Sari }\end{array}$ & $\begin{array}{ll}28 & \text { September } \\
2018 & \\
\end{array}$ & $\begin{array}{l}19 \\
\text { Tahun } \\
\end{array}$ \\
\hline 48 & Linda Purnamasari & 18 Oktober 2018 & $\begin{array}{l}19 \\
\text { Tahun }\end{array}$ \\
\hline 49 & Eva Apriliana & 19 Oktober 2018 & $\begin{array}{l}17 \\
\text { Tahun }\end{array}$ \\
\hline 50 & Nur Laela & 23Oktober 2018 & $\begin{array}{l}19 \\
\text { Tahun }\end{array}$ \\
\hline 51 & Lina Wiwin Safitri & 24 Oktober 2018 & $\begin{array}{l}19 \\
\text { Tahun }\end{array}$ \\
\hline 52 & Fitri Yuliani & $\begin{array}{ll}02 & \text { November } \\
2018 & \end{array}$ & \begin{tabular}{|l|}
19 \\
Tahun
\end{tabular} \\
\hline 53 & Roikhatul Janah & 20 Februari 2019 & $\begin{array}{l}18 \\
\text { Tahun }\end{array}$ \\
\hline 54 & Suci Nurlaela & 01Maret 2019 & 17 \\
\hline
\end{tabular}




\begin{tabular}{|c|l|l|l|}
\hline & & & Tahun \\
\hline 55 & $\begin{array}{l}\text { Siti Kholifatul } \\
\text { Faiqoh }\end{array}$ & 04 Maret 2019 & $\begin{array}{l}\text { 18 } \\
\text { Tahun }\end{array}$ \\
\hline 56 & Malikatur Rosidah & 13 Maret 2019 & $\begin{array}{l}\text { 19 } \\
\text { Tahun }\end{array}$ \\
\hline 57 & $\begin{array}{l}\text { Qoni'atul } \\
\text { Imtikhanah }\end{array}$ & 29 Maret 2019 & $\begin{array}{l}\text { 19 } \\
\text { Tahun }\end{array}$ \\
\hline 58 & Naimah & 06 April 2019 & $\begin{array}{l}\text { 20 } \\
\text { Tahun }\end{array}$ \\
\hline 59 & $\begin{array}{l}\text { Delvira } \\
\text { Gustianti }\end{array}$ & 07 April 2019 & $\begin{array}{l}\text { 20 } \\
\text { Tahun }\end{array}$ \\
\hline 60 & Ita Nova Wulandari & 08 Juni 2019 & $\begin{array}{l}\text { 18 } \\
\text { Tahun }\end{array}$ \\
\hline 61 & Lukfatul Farikhah & 17 Juni 2019 & $\begin{array}{l}\text { 20 } \\
\text { Tahun }\end{array}$ \\
\hline 62 & Afi Nur Maulida & 20 Juni 2019 & $\begin{array}{l}\text { 18 } \\
\text { Tahun }\end{array}$ \\
\hline
\end{tabular}

(Sumber: Data dari Kantor Urusan Agama)

Dari data yang diambil oleh peneliti merupakan data pelaku pernikahan dini dimulai dari Tahun 2016, 2018 sampai 2019.Agar nantinya dapat digunakan sebagai perbandingan dan dapat dilakukannya tindakan dalam upaya pencegahan pernikahan dini.

Faktor yang mempengaruhi pernikahan dini ada dua kategori yaitu Faktor Internal dan Eksternal. Adapun faktor-faktr internal tersebut adalah: Faktor pendidikan, Faktor Hubungan biologis, dan Hamil sebelum waktunya.

Tingkat pendidikan yang rendah membuat remaja yang seharusnya sibuk dengan belajar menjadi tidak ada aktifitas yang jelas.Maka hal tersebut mendorong untuk berpacaran dan pada akhirnya dinikahkan. Kemudian karena anak-anak telah melakukan hubungan biologis layaknya suami-istri, maka orang tua dari anak perempuan cenderung segera menikahkan anaknya, karena menurut orang tua anak gadis ini sudah tidak perawan lagi, dan hal ini menjadi aib. Selanjutnya Faktor Hamil sebelum waktunya yang dalm hal ini bukan hanya kecelakaan tetapi biasanya juga karena di perkosa sehingga terjadilah hamil sebelum 
waktunya, orang tua yang dihadapkan seperti ini pastilah akan menikahkan anakanya karna di anggap sebagai aib keluarga.

Sedangkan Faktor Eksternal yang mempengaruhi perniahan dini adalah: Faktor ekonomi dan Faktor orang tua. Faktor ekonomi biasanya terjadi ketika keluarga si gadis berasal dari keluarga kurang mampu. Orang tuanya pun menikahkan si gadis dengan laki-laki dari keluarga mapan. Hal ini tentu akan berdampak baik bagi si gadis maupun orangtuanya. $\mathrm{Si}$ gadis bisa mendapat kehidupan yang layak serta beban orangtuanya bias berkurang. Selian itu Faktor orangtua yang mana Orang tua yang mendorong anaknya untuk menikah di usia muda juga disebabkan oleh banyak hal diantaranya yaitu pemahaman agama orang tua. Sebagian orang tua begitu kurang dalam memahami ajaran agamanya dengan dalih, bahwa menikah muda dapat menjauhkan anak dari perbuatan negatif tanpa memedulikan aspek lainnya ataupun yang telah ditetapkan.Selain itu, rendahnya tingkat pendidikan orang tua juga memicu terjadinya pernikahan dini.

Dari penjelasan diatas dapat ditawarkan beberapa solusi yang mungkin bisa dilakukan agar setidaknya mengurangi dari angka pernikahan dini. faktor-faktor penyebab pernikahan dini khususnya di Desa Tegalsari Kecamatan Tegalsari Kabupaten Banyuwangi diantaranya sebagai berikut:

Mengubah kebiasaan masyarakat melakukan pernikahan dini dengan memberikan penyuluhan-penyuluhan mengenai umur yang ideal untuk melakukan perkawinan serta memberikan penjelasan-penjelasan mengenai sebab akibat melakukan pernikahan dini, positif dan negatifnya pernikahan di usia dini.

Memberikan pengetahuan akan pentinya pendidikan, dengan menempuh pendidikan setidaknya menunda pernikahan terlebih dahulu. Dengan melakukan pendidikan setidaknya dapat mengurangi faktor penyebab dari pernikahan dini. 
Melakukan penyuluhan di sekolah-sekolah dengan memberikan wawasan tentang pernikahan dini terutama ditingkat SMP/SMA sederajat. Serta memberikan pengetahun tentang peran sebuah keluarga, peran seorang istri, peran sorang ayah, dan kewajiban seorang anak.

Peranan perangkat hukum, seperti pengawasan yang di lakukan oleh pegawai pencatat nikah, peranan pengadilan agama atau pejabat selaku pemberi dispensasi. Memberikan hukuman yang jelas kepada para pelaku zina, karena pada faktanya banyak pelaku yang terpaksa nikah dini karena kehamilan diluar nikah. Jika hal tersebut dilaksanakan maka setidaknya bisa mengurangi terjadinya pernikahan dini.

\section{D.Kesimpulan}

Dari pemaparan data diatas dapat ditarik kesimpulan bahwa di Desa Tegalsari Kecamatan Tegalsari Kabupaten Banyuwangi. Peneliti Telah menemukan ada dua faktor penyebab pernikahan dini yaitu faktor internal meliputi: Faktor Pendidikan, Faktor Hubungan Biologis, dan Hamil Sebelum Waktunya. Sedangkan Faktor Eksternal itu sendiri meliputi: Faktor Ekonomi, dan Faktor Orang tua.

\section{Daftar Pustaka}

Lestani, SRI. 2012. Psikologi Keluarga: Penanaman Nilai dan Penanganan Konflik dalam Keluarga. Penerbit Kencana Prenada Media Group.

Darajadjat, Zakariyah. 1982. Pembinaan Remaja. Penerbit N.V. Bulan Bintang- Jakarta 1982.

Geldard, Kathryn. \& Geldard, David. 2011. Konseling Remaja. Penerbit Pustaka Pelajar.

Http://nasional.sindonews.com.di akses 5Mei 2019

www.desisachiko.com, diakses 02 Maret 2019

Hasballah, Fachruddin. 2008. Psikologi Keluarga dalam Islam. Penerbit Yayasan Pena Banda Aceh, Devisi Penerbitan.

Hamidi, 2004. Metode Penelitian Kualitatif. Malang: Universitas Muhammadiyah Malang.

F.J. Monks-A.M.P Knoers, Haditono, Siti, Rahayu. 2002. Psikologi Perkembangan. Pengantar Berbagai Bagiannya. Penerbit Gadjah Mada University Press.

Sugiyono. 2015. Metode Penelitian Kuantitatif, Kualitatif dan R\&D. ALFABETA, CV 
Khasanah, Nginayatul. 2017. Pemikahan Dini Masalah dan Problematika. Penerbit AR-RUZZMEDIA

Soekanto, Soerjono. 2009. Sosiologi Keluarga Tentang Ikhwal Keluarga, Remaja dan Anak. RINEKA CIPTA

Http://Psikologi.com.Konseling Pranikah di akses 06 Agustus 2019

Walgito, Bimo. 2017. Bimbingan dan Konseling Pekawinan. C.V ANDI OFFSET Yogyakarta

Yusuf, Syamsu \& A. Juntika Nurihsa. 2008. Landasan Bimbingan \& Konseling. PT REMAJA ROSDAKARYA

Corey, Gerald. 2013. Teori dan Praktek KONSELING \& PSIKOTERAPI. PT Refika Aditama Bandung. 